\title{
CORPO E MODA: USO DA CALÇA CINTA MODELADORA
}

\author{
Body And Fashion: Pants Belt Use Modeling \\ Almeida,Sara Girão Borges; Especialista; SENAC -CE, \\ saragbalmeida@hotmail.com ${ }^{1}$; \\ Almeida, Regina Célia S.; Mestre; Faculdade \\ Ateneu;regina.almeida@fate.edu.br ${ }^{2}$ \\ Cabral, Mara Raquel Marinho; MBA e Especialista; Faculdade \\ Ateneu;Raquel.marinho@fate.edu.br ${ }^{3}$
}

\begin{abstract}
Resumo:
O presente estudo aborda o desenvolvimento de um produto inovador voltado para delinear o contorno da silhueta feminina, com base nos estudos de Baxter (2011), Grave (2004), Lida (2005). Trata-se de uma pesquisa qualitativa, exploratória e experimental cujos dados coletados por entrevistas sobre o grau de satisfação das usuárias, serão analisados pela escala de Likert.
\end{abstract}

Palavras-chave: Cinta, feminina, projeto.

\section{Abstract:}

This study addresses the development of an innovative product designed to outline the contours of the female figure, based on Baxter (2011), Grave (2004), Lida (2005). This is a qualitative, exploratory and experimental research which data collected by interviews on the degree of satisfaction of users, will be based on the Likert scale.

Keywords: Belt, feminine, design.

\section{Introdução}

Em um revival constante as calças Saint-Tropez vedete dos anos 60, aparece nas passarelas em suas releituras, e por consequência vira objeto de desejo do consumidor final. Os corpos esbeltos das modelos, passarelas encantadoras, campanhas publicitárias repletas de signos e desejos, entre

\footnotetext{
${ }^{1}$ Tecnóloga em Design de Moda - Faculdade Ateneu; Especialização em Gestão do Design de Moda (em andamento) Faculdade Ateneu; - Reality Project com Jum Nakao - Costureiro e artesão Fortaleza - Ce Casa de Criadores (Evento) 2012 -Reality Project com Jum Nakao - Costureiro e artesão São Paulo - SP

${ }^{2}$ Mestre em Politicas Publicas e Gestão da Educação Superior- UFC; Especialista em Gestão Universitaria UFC; Bacharel em Estilismo e Moda UFC; Professora e Coordenadora de CST Tecnologia em Design de Moda e da Pós Graduação em Gestão do Design - Fac. Ateneu-Ce: Avaliadora Basis INEP/MEC

3 MBA em Marketing pela FGV; Especialização em Criação de Imagem e Styling de Moda Senac SP;Tecnológa em Estilismo e Moda-Faculdade Católica do Ceará. Estilista de lingeries e Coordenadora de desenvolvimento de produto; professora no curso Design de Moda da Faculdade Ateneu .
} 
outros elementos caracterizam fatores que influenciaram e estimularam o uso das roupas de cintura baixa por longo tempo. A moda da cintura baixa atingiu mulheres de todas as classes sociais, vários biótipos e ampla faixa etária, abrangendo desde jovens adolescentes a mulheres contemporâneas com idade pouco superior aos cinquenta anos. Essa referência do vestuário permaneceu na moda por cerca de duas décadas, onde as peças mais evidenciadas para o uso foram basicamente saias, shorts, calças compridas com gancho curto e forte tensão do cós sobre a região abaixo da linha da cintura, o apelo sensual associado à oferta de roupas com cós cada vez mais baixos, exigiram o uso de roupas íntimas cada vez menores, com alturas mínimas e laterais mais estreitas, a exemplo a calcinha string ${ }^{4}$, provocando uma dupla tensão no tecido da região pélvica, sobretudo, se a usuário permanecesse longo tempo de uso em posições que influenciavam ainda mais essa pressão, como exemplo, se a usuária permanecesse sentada por muito tempo, o que potencializava a marcação do cós nessa região criando assim uma segunda linha da cintura.

Muitas dessas mulheres, depois de alguns anos usando demasiadamente a calça de cinta baixa, perceberam que sua silhueta apresentava uma deformação, uma nova linha abaixo da cintura e pouco acima da região pélvica surgiu, uma leve depressão no tecido adiposo para algumas consumidoras, maior afundamento para outras mulheres, deformidade que variava conforme biótipo, uma marca no corpo localizada exatamente no ponto de contato e pressão contínua do cós da calça Saint-Tropez sobre aquela região do corpo, o desenho do cós num formato imaginário se definiu, ou seja, ele, o cós não estava no corpo, mas a sua anatomia sim, a formação de uma depressão definida na pele das usuárias, intensificada em mulheres com tecido adiposo de maior espessura.

Com isso, as mulheres que se sentiram constrangidas com tais depressões na pele, buscaram soluções estéticas de várias formas, utilizando procedimentos estéticos como lipoaspiração, tratamentos crioterápicos, entre outros, no entanto, um fator para maior eficiência desses tratamentos chamou

\footnotetext{
${ }^{4}$ String - Peça de roupa íntima caracterizada por ter gancho de baixa altura cobrindo basicamente a região pubiana, com laterais extremamente finas estruturadas apenas por tiras elásticas.
} 
atenção, a indicação de peças para o pós-procedimento, trata-se de peças do vestuário prescritas pelo profissional às pacientes, o uso de cintas modeladoras por determinado tempo (conforme a necessidade de cada técnica utilizada, podendo variar entre 15, 30 e 60 dias), espécie de calcinhas com altura acima da linha da cintura em tecido de alta compressão, com objetivo de reduzir os impactos dos inchaços causados após e por causa do procedimento. Nesse sentido, seria realmente uma necessidade a utilização de procedimento estético? Será que o uso da calça cinta aliado a exercícios físicos e uma dieta para redução do peso e a abstenção do uso das peças de cintura baixa não solucionaria esse problema? Essa peça modeladora poderia ser tornar a solução para remodelar a silhueta para consumidoras que não podem, ou não querem passar por um procedimento estético?

Vale ressaltar que o estudo em pauta se limita a apresentar o projeto de um produto, sendo uma calça cinta modeladora e resultado do seu pré-teste, medido pelo grau de satisfação das usuárias em relação aos supostos efeitos de correção das alterações das silhuetas, seja temporária - quando em uso, ou permanente - após uso. Não contará com variáveis relacionadas à redução de peso ou tratamentos estéticos.

O produto em estudo visa atender a necessidade do vestuário íntimo feminino em relação à funcionalidade, anatomia e conforto. Trata de uma peça do vestuário que visa proporcionar um conforto estético valorizando a silhueta atrelado a segurança da compressão através de tecidos com altos níveis de elastano ${ }^{5}$ que propicia maior força de compressão, sendo uma roupa íntima com atributos ergonômicos, para o uso diário, tendo como principal característica a compressão do glúteo, bem como, da região abdominal e pélvica.

A roupa é um produto, sendo assim a calça cinta modeladora é um artigo do vestuário para o uso diário capaz de remodelar o corpo, respeitando os movimentos, promovendo segurança, conferindo conforto físico e emocional. Portanto, o projeto do produto do presente estudo objetiva evitar e corrigir possíveis deformações corporais, especificamente no tecido adiposo,

\footnotetext{
${ }^{5}$ Elastano - Na indústria têxtil trata-se de uma fibra de composição sintética com base elástica, sua capacidade de alongamento pode chegar a $500 \%$.
} 
causada por marcas do uso contínuo de roupas com tamanhos e tensões inadequadas. Determina ainda a valorização do corpo feminino na forma física, anatômica e ergonômica, por se tratar de uma peça desenvolvida para o uso cotidiano, a modelagem traz reforços estratégicos e recortes que contribuam para a compressão, correção e realce das curvas femininas, sobretudo, nos glúteos, nas regiões abdominal e pélvica, o projeto contempla ainda uma apresentação estética funcional.

A idealização deste produto é inspirada da silhueta feminina, por ser a mulher brasileira dotada de um corpo curvilíneo, é perceptível que a modelagem de algumas lingeries não valorizam ou consideram algumas partes do corpo, muitas vezes valorizando a beleza da parte estética e não respeitando as questões ergonômicas e funcionais. Lehnert (2000,p. 12) afirma que "Poiret defendia que se deveria mostrar a beleza natural do corpo feminino".

Thomas (2009), afirma que por meio da moda é possível perceber os hábitos e comportamentos de uma época e as revoluções da moda sempre seguiram as revoluções históricas, principalmente, na questão social da mulher. No caso da lingerie, tema pouco discutido em trabalhos científicos, mesmo se tratando de um produto de moda que, na maioria das vezes, fica escondido, expressa um caráter misterioso. Thomas(2010) ressalta que, por ser uma roupa de baixo, traz confiança à mulher e pode moldar seu corpo da forma como ela idealiza, o que a faz construir uma relação de satisfação com ele. Trata-se de uma vestimenta íntima que, assim como as demais roupas, já acumulou diversas funções e sempre expressou, principalmente, a realidade feminina - desde que servia para esconder as partes íntimas , PIVETEAU(2005).

As cintas modeladoras disponíveis no mercado possuem aparência simples, semelhantes para todos os modelos e configuração visual não associada à beleza, tendo como função reduzir medidas por compressão da malha, manter a sinuosidade da silhueta com conforto. Essas peças, em sua maioria não possuem costuras, são como segunda pele. Porem, essas peças tem preços elevados, o que dificulta o acesso a mulheres de baixo poder aquisitivo. 


\section{O produto e suas funções}

O presente estudo trata-se de uma pesquisa qualitativa, explicativa de caráter experimental, haja vista que o objeto do estudo consiste na confecção de um produto de uso pessoal e a verificação do efeito da função prática proposta pelo criador, de acordo com conceito de Gil (2008) sobre tipos de pesquisa.

O projeto desse produto em estudo foi elaborado com base nos dois processos de BAXTER (2000), o Gerenciamento das atividades e o Controle de qualidade do desenvolvimento do produto, bem como inspirado no ciclo PDCA (Plan, Do, Chek, Action), afim verificar as três funções de uma peça de moda íntima funcional feminina: preservar, prevenir e corrigir as imperfeições da linha do contorno da região abdominal/pélvica femininas.

A pesquisa foi aplicada a 30 (trinta mulheres) com idade entre 25 e 55, usuárias de peças do vestuário íntimo comum (calcinhas convencionais), bem como do vestuário esporte (calças e shorts de ganchos pequenos e cintura baixa) que, marcam a linha quadril e que já possuam a deformação nesta linha na silhueta. As participantes devem ter o índice de massa corporal em torno de 28 a 30 IMC.

As participantes foram divididas em 3 grupos, Grupo 1 - Tempo de uso 2 meses; Grupo 2 - tempo de uso 4 meses; e Grupo 3 - Tempo de uso 6 meses.

Pretende-se distribuir 5 (cinco) calças modeladoras para uso diário às participantes, as quais serão aplicados questionários antes e depois do tempo de uso para averiguar o grau de satisfação com o produto.

Nesta primeira fase da pesquisa, conceituada por pré-teste 1 , o tempo da pesquisa experimental foi de 2 meses, e as participantes precisavam se comprometer a não aumentar de peso durante a pesquisa.

Por tratar-se de uma peça íntima modeladora, houve um cuidado no desenvolvimento de uma modelagem ergonomicamente correta; a escolha da matéria-prima e controle da produção industrial. Contemplou-se, também, o uso de aviamentos de acabamento (viés e elástico). 
O modelo da peça em questão objetiva atender diretamente o desejo e a satisfação da consumidora, objetivando resultado mais satisfatório do produto ao ser comercialmente positivo, tendo uma ligação entre os meios técnicos e a fabricação do produto.

Com as análises qualitativas através das consumidoras entrevistadas, separadas por suas diferentes faixas etárias, foi realizada a triangulação de opiniões, para medir o grau de satisfação com o produto em relação ao conforto, qualidade e funcionamento.

Figura 1- Croqui 01a

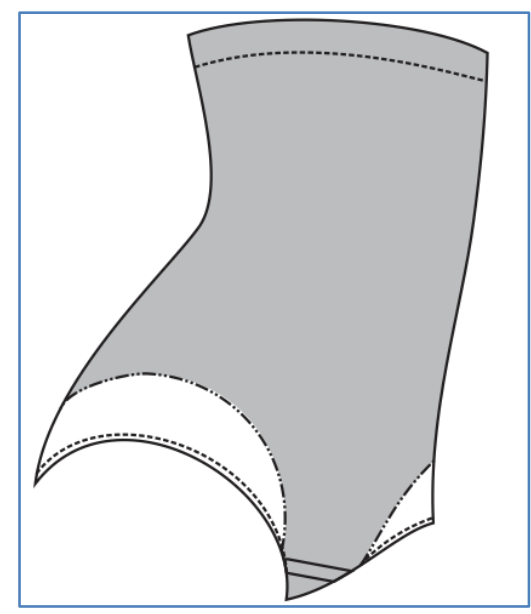

Figura 2- Croqui 01b 
12 Colóquio de Moda - 9a Edição Internacional 3 Congresso de Iniciação Científica em Design e Moda

2016

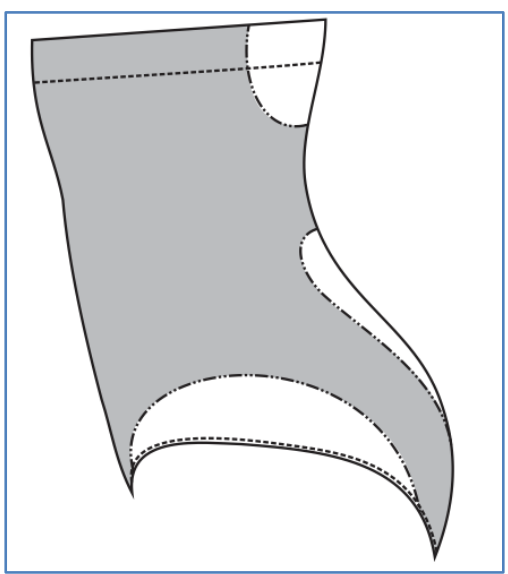

Figura 3- Croqui 01c

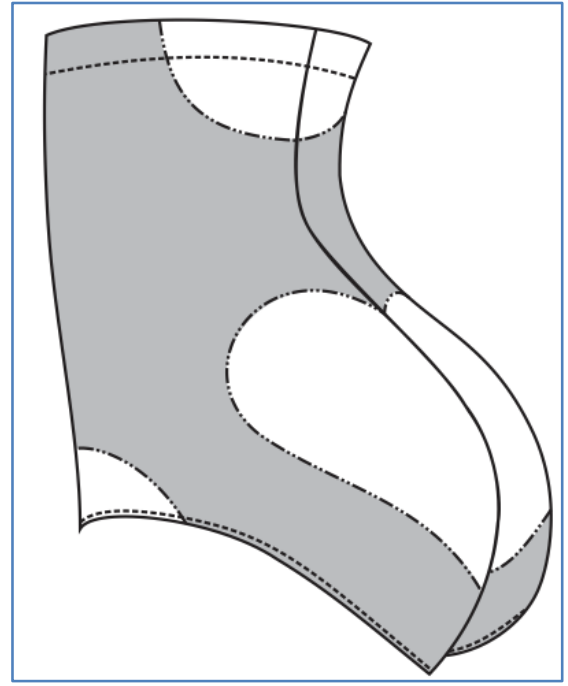

Bases Conceituais do produto - características e processos de produção Figura 4 - Ficha Técnica 
12 Colóquio de Moda - 9a Edição Internacional 3 Congresso de Iniciação Científica em Design e Moda

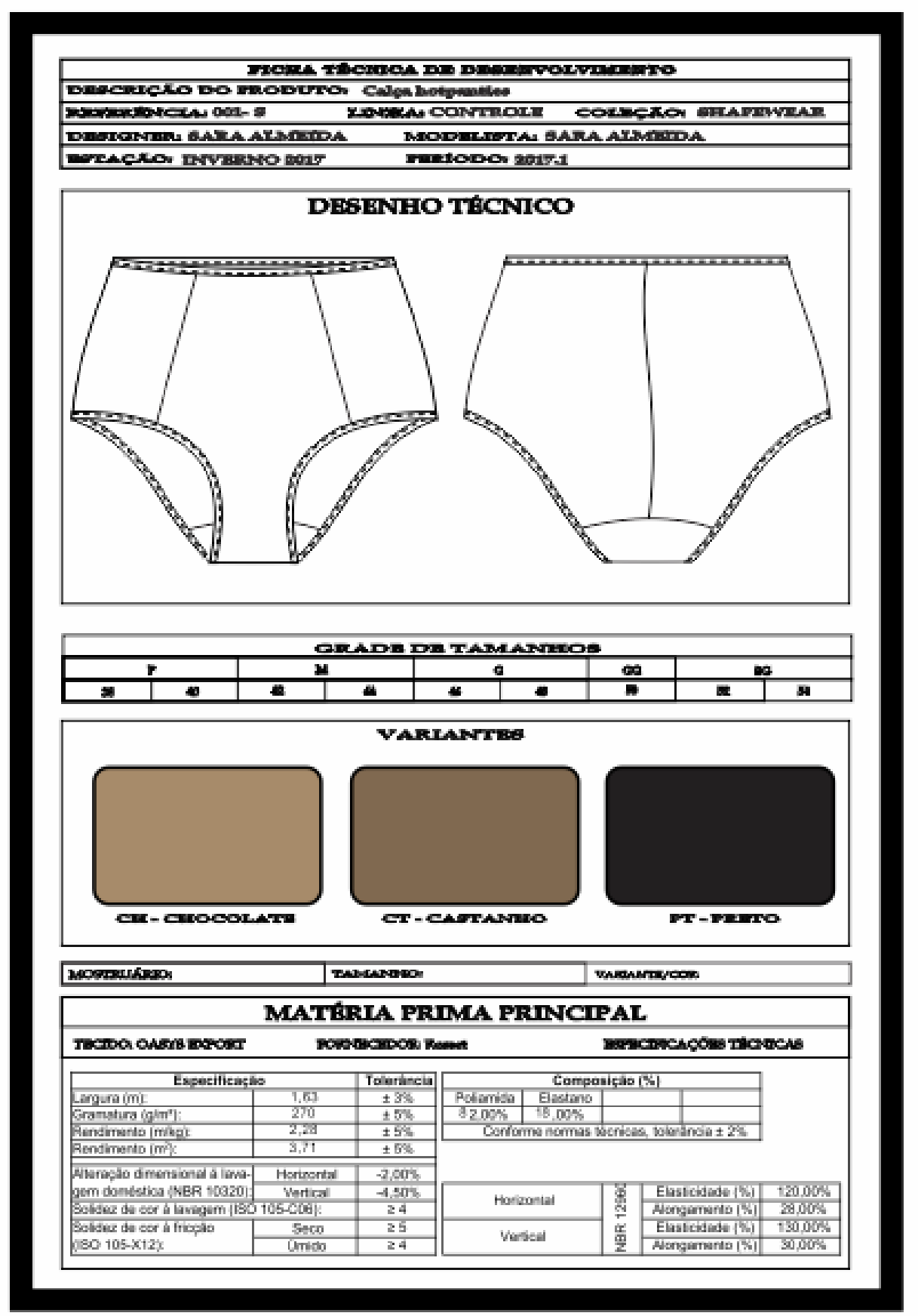

A figura 4 trata da divisão de ficha-técnica que indica referência, descrição do produto, linha e coleção, traz ainda desenho técnico que detalha parte do processo de design, informação de variantes para a cartela de cor, informações do tecido principal como gramatura, rendimento, composição, alongamento e elasticidade. 
12 Colóquio de Moda - 9a Edição Internacional 3 Congresso de Iniciação Científica em Design e Moda

Figura5 - Ficha Técnica

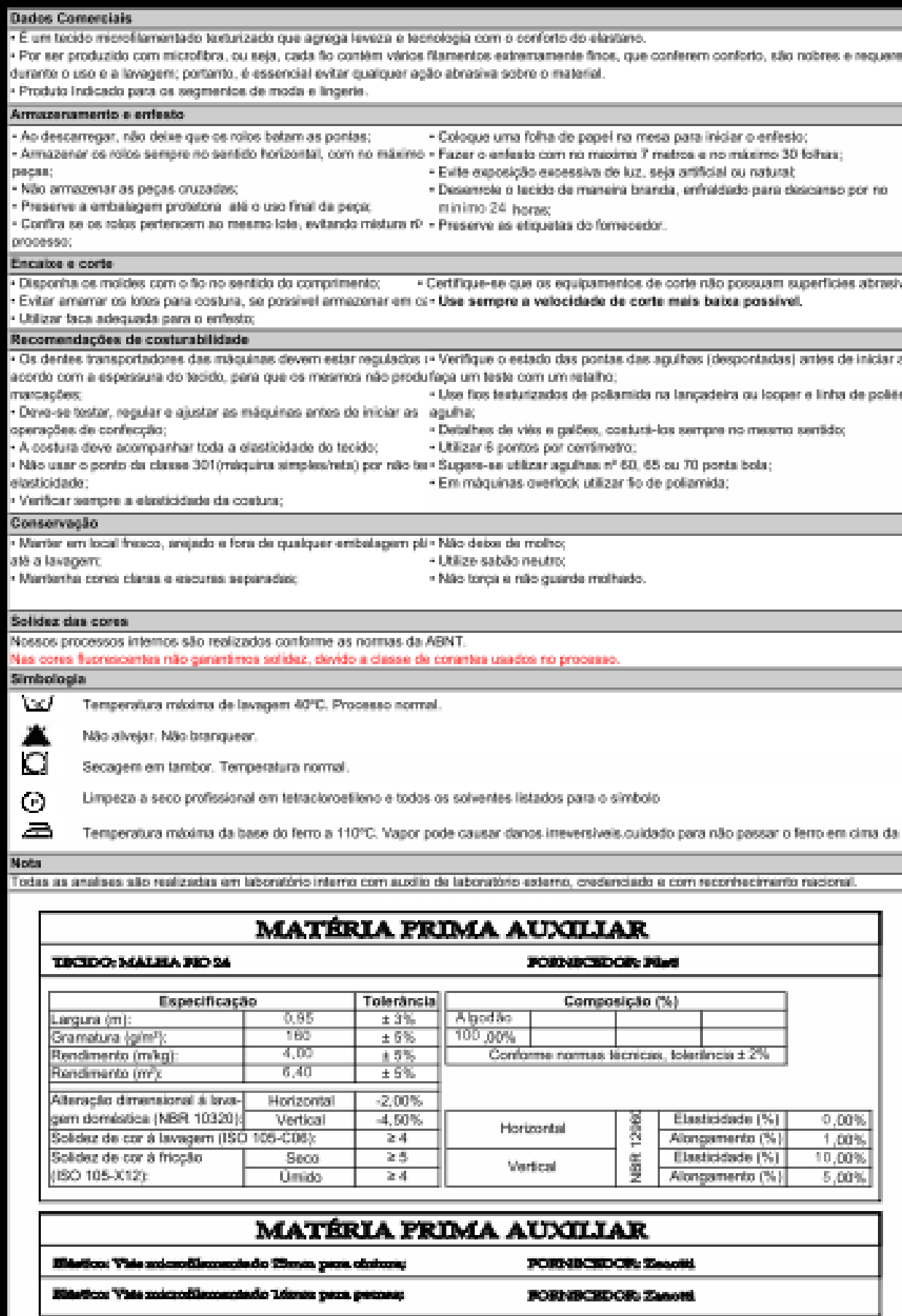

A figura 5 da ficha técnica informa dados comerciais do tecido principal, os tipos adequados de armazenamento e enfesto, orientações para encaixe e 
12 Colóquio de Moda - 9a Edição Internacional 3 Congresso de Iniciação Científica em Design e Moda

corte, traz ainda as recomendações de costurabilidade e indica as advertências de conservação, bem como, os informes de solidez de cores e a simbologia, no qual deverá ser utilizada na etiqueta de composição do produto final. $\mathrm{O}$ tecido auxiliar também é dado conhecimento na ficha técnica, que traz informação da composição, gramatura, rendimento, alongamento e elasticidade.

Figura 6 - Ficha Técnica

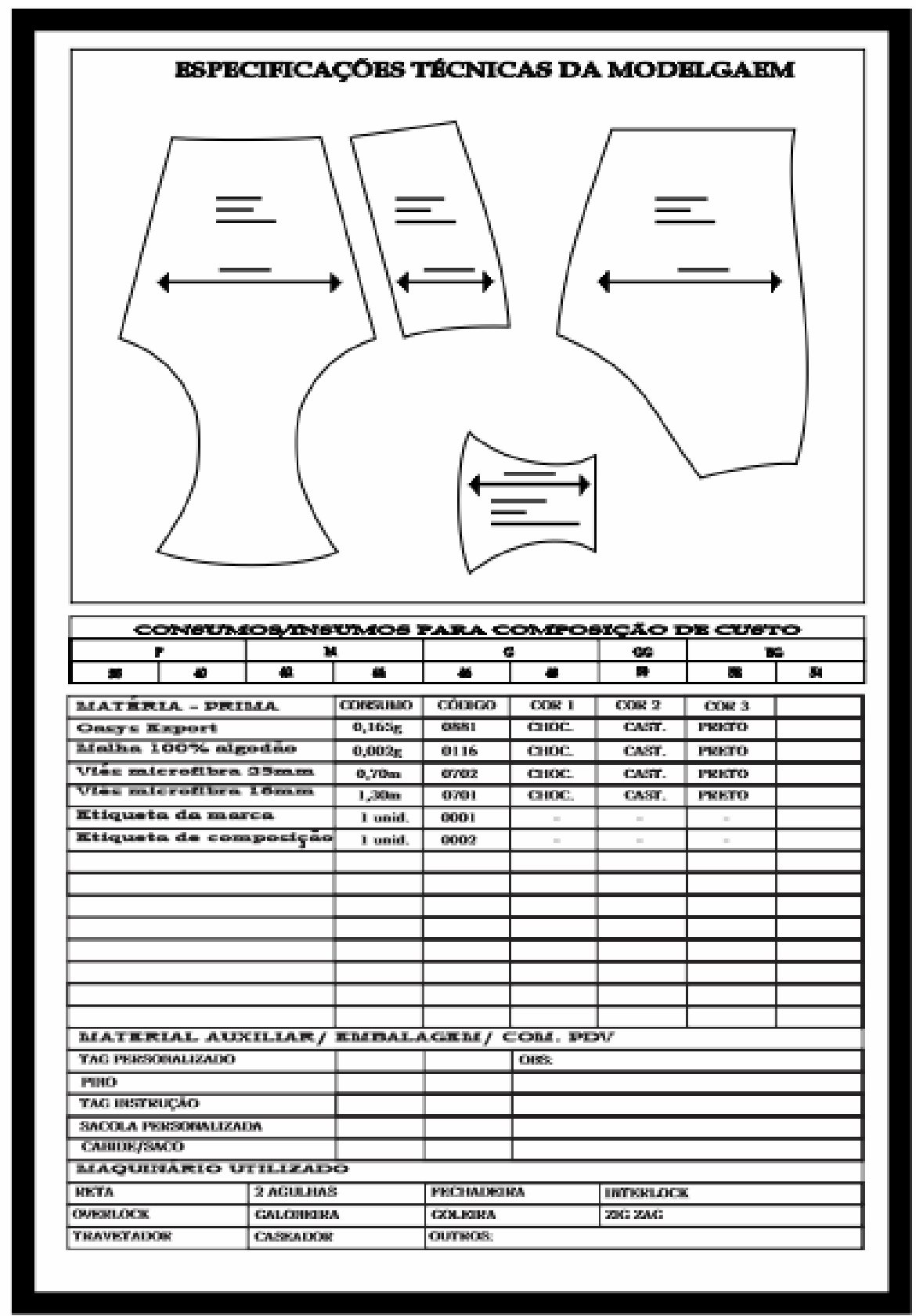

A figura 6 constitui parte da ficha-técnica que informa as formas da modelagem, indica os tecidos para cada elemento da modelagem, indica 
12 Colóquio de Moda - 9a Edição Internacional 30 Congresso de Iniciação Científica em Design e Moda

posição do fio frente a trama e ao urdume, traz ainda o detalhamento de todos os insumos, bem como, a quantidade utilizada para a formação do custo.

A ficha técnica estabelece as bases conceituais de cada produto, traz as configurações e características necessárias que detalham as etapas esquemáticas do desenvolvimento de produtos, bem como, direcionam os processos gerencias de cada processo a ser executado durante a manufatura, levantamento e mensuração de custos até que o produto final seja embalado e direcionado ao setor comercial.

\section{Resultados e Análises do Pré-teste}

A pesquisa foi aplicada a 15 mulheres que usaram o produto durante dois meses, o pré-teste 1. Elas foram separadas por suas diferentes faixas etárias, foi feita a triangulação de opiniões para aumentar o grau de verdade das respostas.

.O pré-teste 1 revelou que o modelo da peça em questão solucionou temporariamente o problema de $85 \%$ das consumidoras, que afirmaram que durante o uso a deformação corporal não era percebida, além da peça lhe dar a sensação de musculatura mais rija e silhueta mais esguia e não apresentar marcas de costuras nas peças externas

Quanto às motivações que mais induziram as entrevistadas a aprovar o uso do produto (calça cinta modeladora), foi ressaltado em primeiro lugar o fator estético pelo fato do produto ter corrigido temporariamente a silhueta; em segundo lugar, o conforto e a segurança, ambos ligados ao campo sensorial, fatores importantes para aprovação passar para o teste 2 que verificará do lançamento do produto.

\section{Considerações Finais}

O presente projeto apresentou um novo produto que proporcionará, sobretudo, conforto e segurança às consumidoras. Este produto foi inspirado a partir do formato físico feminino e adequado à região pélvica. Sabe-se que o uso contínuo de certas modelagens vem comprometendo a forma natural do corpo feminino, além de gerar várias consequências indesejáveis. Um objeto 
12 Colóquio de Moda - 9a Edição Internacional 3 Congresso de Iniciação Científica em Design e Moda

representa bem mais que a materialidade e a funcionalidade, pois sua existência relaciona-se com a vida do consumidor.

\section{Referências Bibliográficas}

BAXTER, M. Projeto de Produto - Guia prático para o design de novos produtos. $3^{a}$ Ed., São Paulo: Editora Edgard Blücher, 2011.

GRAVE, Maria de Fatima. A modelagem sob ótica da ergonomia. São Paulo. Zennex. 2004

GIL, Antonio Carlos. Como elaborar projetos de pesquisa. 4. ed. São Paulo: Atlas, 2008.

IIDA, Itiro. Ergonomia: projeto e produção. São Paulo: Edgard Blucher, 2005.

MARTINS, Suzana Barreto. O conforto no vestuário: uma interpretação da ergonomia: metodologia de avaliação de usabilidade e conforto no vestuário. 2005. Tese (Doutorado em Engenharia de Produção) - Universidade Federal de Santa Catarina, Florianópolis, 2005.

. Equação da ergonomia no design de vestuário: espaço do corpo, modelagem e matérias. In: CONGRESSO BRASILEIRO DE ERGONOMIA ABERGO, 14., 2006, Curitiba - PR . Anais... Curitiba: ABERGO, 2006.

MEDEIROS, Maria de Jesus Farias. Produto de moda: modelagem industrial com aspectos do design e da ergonomia. Palermo, Universidade de Palermo, 2007.

MESQUITA, C. Moda Contemporânea: quatro ou cinco conexões possíveis. São Paulo: Editora Anhembi Morumbi, 2002.

LEHNERT, G. História da Moda do Século XX. Colônia: Konemann, 2000. 